\title{
Mathematics and biology teachers' tacit views of the knowledge required for teaching: varying relationships between CK and PCK
}

\author{
Ronit Rozenszajn and Anat Yarden*
}

\begin{abstract}
Background: The knowledge that is required for teaching includes subject matter content knowledge $(\mathrm{CK})$ and pedagogical content knowledge (PCK). Although CK and PCK are distinct components of the teachers' knowledge, the distinction between those two components and the relationships between them are still underexplored. In a previous study, we showed that biology teachers that participated in a long-term professional development program view CK as an important component of the knowledge required for teaching biology, yet they see it as distinct from PCK. We wondered what are the views of mathematics teachers, who participate in a similar program, on the knowledge that is required for teaching and on the relationships between CK and PCK. In addition, we compared the participating mathematics and biology teachers' tacit views of the knowledge required for teaching and on the relationships between CK and PCK.

Results: We used the Repertory Grid Technique (RGT) as well as semi-structured interviews and a focus group, to elicit mathematics $(n=13)$ and biology $(n=16)$ teachers' tacit views about the knowledge that is required for teaching. The results show that both mathematics and biology teachers view CK as a significant component of their teaching practice. However, whereas mathematics teachers tend to view CK and PCK as related entities, biology teachers tend to view them as separate.

Conclusions: The main contribution of this study is in exposing that teachers from different disciplines may view differently the importance of high-level CK to their practice. The differences among the participating mathematics and biology teachers' tacit views of the relationships between CK and PCK may aid in the design of professional development programs for mathematics and biology teachers. It is important to draw attention to the ability to recognize the tacit relationships between CK and PCK and to articulate these relationships in planning professional development programs.
\end{abstract}

Keywords: Pedagogical content knowledge; Content knowledge; Tacit views; Professional development

\section{Background}

Teachers' knowledge base is crucial for their professional development. Shulman (1986) first suggested that there are three domains of knowledge that are required for teaching: pedagogical content knowledge (PCK), subject matter content knowledge (CK), and curricular knowledge. PCK was defined as a special amalgam of content and pedagogical knowledge that is unique and describes the ways of representing and formulating the subject to

\footnotetext{
* Correspondence: anat.yarden@weizmann.ac.il

Department of Science Teaching, Weizmann Institute of Science, Rehovot 76100, Israel
}

make it comprehensible to others (Shulman 1986, 1987). CK was defined as the amount and organization of subject matter knowledge per se in the mind of a teacher, and curricular knowledge was defined as the full range of programs designed for the teaching of a particular subject at a particular level (Shulman 1986).

Several previous studies have examined the relations between teachers' CK and PCK. The distinction between $\mathrm{CK}$ and PCK has been shown to be helpful in identifying the kinds of knowledge that play an important role in teachers' learning (Ball et al. 2008). Although CK and PCK are distinct components of teachers' knowledge, it has been suggested that it is impossible to distinguish 
CK from PCK (Marks 1990; Fernandez-Balboa and Stiehl 1995). Some researchers suggest that enhanced CK may afford teachers a broader and more varied repertoire of teaching strategies (Krauss et al. 2008; Ball et al. 2008; Baumert et al. 2010; Even 2011), while limited CK has been shown to be detrimental to PCK, limiting the scope of its development (Baumert et al. 2010). Conversely, other studies have shown that broad CK in a discipline does not guarantee that teachers will use it effectively in their classroom practice (Zeidler 2002; Rozenszajn and Yarden 2014a). In a previous study, we showed that biology teachers that participated in a long-term professional development program view $\mathrm{CK}$ as a very important component of the knowledge required for teaching biology, yet they see it as distinct from PCK (Rozenszajn and Yarden 2014a). In light of these findings, we wondered whether mathematics teachers that participated in the same professional development program will have similar or different views on the knowledge that is required for teaching and on the relationships between CK and PCK. Since, the current literature about the distinction between CK and PCK within mathematics teachers' knowledge is still a subject of debate (Depaepe et al. 2013); this study may shed light on this debate and may contribute to our understanding of the possible differences that may exist between views of teachers about the knowledge that is required for teaching various scientific disciplines.

This study is focused on the participating mathematics teachers' views of the knowledge required for teaching and on the relationships between CK and PCK in particular. Furthermore, this study compares the participating mathematics and biology teachers' views of the knowledge required for teaching and on the relationships between CK and PCK.

\section{The relationships between PCK and CK}

Shulman (1986) first suggested that there are several types of knowledge that are required for teaching, including CK and PCK. A considerable effort has been made in the last three decades to construct a well-established conception of science teachers' professional knowledge (e.g., Ball et al. 2008; De Jong and Van Der Valk 2007; Lee and Luft 2008; Loughran et al. 2001; Loughran et al. 2008; Magnusson et al. 1999). Although both CK and PCK are considered critical professional development resources for teachers, each requiring special attention during teacher training and classroom teaching practice (Baumert et al. 2010), teachers' professional knowledge is still difficult to define and articulate (Berry et al. 2008). Moreover, PCK is highly topical, personal, and situation specific. Therefore, professional development programs aimed at developing teachers' PCK should provide opportunities to enact and reflect their PCK in addition to their theoretical studies (Van Driel and Berry 2012).
Several studies have discussed the possible relationships between teachers' CK and PCK and their influence on teaching without reference to a specific discipline. For example, Grossman (1990) suggested that beginning teachers tend to rely more heavily on one domain of knowledge, whereas experienced teachers are able to integrate all of the domains in their practice. Lederman and Gess-Newsome (1992) suggested examining the relationships between CK and PCK in analogy to the ideal gas law. They concluded that one should not assume that an improvement in teachers' CK will automatically translate into improved PCK, in the same manner in which increased volume of a container will decrease the pressure of a gas's constant temperature. Zeidler (2002) agreed that increased teachers' CK does not necessarily affect their PCK, but argued that the act of teaching influences teachers' CK.

Studies relating to a specific discipline while examining the relationships between teachers' $\mathrm{CK}$ and PCK are rather rare. It has been shown that when $\mathrm{CK}$ is more secure, chemistry teachers are better able to match the content to the teaching explanations. In contrast, when teachers experience difficulty in understanding the subject matter, they seem to be less effective teaching it (Childs and McNicholl 2007; Rollnick et al. 2008).

A notable point of disagreement refers to the relationships between CK and PCK in mathematics education. Some authors consider teachers' CK and PCK as distinct constructs, whereas others consider (a part of) CK to be covered by PCK (Depaepe et al. 2013). It has been suggested that the degree of correlation between CK and PCK among secondary mathematics teachers is a function of the level of their mathematical expertise (Krauss et al. 2008). Moreover, mathematical CK has been suggested to enhance mathematics teachers' PCK (Kleickmann et al. 2013). The breadth, depth, and flexibility of teachers' understanding of the mathematics they teach afford them a broader and more varied repertoire of teaching strategies (Krauss et al. 2008; Ball et al. 2008; Even 2011; Baumert et al. 2010) and also deepen their understanding of students' thinking and conceptual understanding (Borko 2004). Moreover, limited CK in these teachers may limit the development of their PCK (Baumert et al. 2010; Kleickmann et al. 2013). Conversely, Hollon et al. (1991) showed that broad CK in mathematics does not guarantee that teachers will use it effectively in class.

A review of the PCK concept and its relations with CK in mathematics education described two different types of research: i) studies investigating the relationships through teachers' classroom practices that stressed the strong correlation between the two different knowledge types within the act of teaching, and ii) studies using distinct test items to measure CK and PCK that showed that both knowledge types are positively correlated and 
that CK is a necessary, though not sufficient, condition for PCK (Depaepe et al. 2013). In biology education, possible relationships between biology teachers' CK and PCK have been recently measured and found to be low (Juttner et al. 2013). We recently found that biology teachers often declare that they are very interested in acquiring new CK in biology because they have to stay updated with the continuous flow of new findings in their field. Yet, CK is viewed by them as an important component of the knowledge required for teaching but by and large as distinct from PCK (Rozenszajn and Yarden 2014a).

An examination of the relationships between teachers' PCK and CK should also take into account that teachers' knowledge is comprised of both explicit and implicit components (Ainley and Luntley 2006; Loughran et al. 2001). While many studies have explored teachers' explicit PCK (e.g., Schmelzing et al. 2013), little attention has been paid to teachers' implicit views of PCK, CK, and the relationships between them (Rozenszajn and Yarden 2014a). In this study, we focus on the views of the participating mathematics teachers on the knowledge required for teaching and on the relationships between CK and PCK. In addition, we compared the participating mathematics and biology teachers' tacit views of the knowledge required for teaching and on the relationships between CK and PCK.

\section{Exploring implicit views}

Implicit views are tacit, contextual, and situated. Each person holds implicit views about something that he or she will be unable to verbalize and often, will be unaware of, namely, they remain tacit (Polanyi 1966). Experts usually hold a large number of tacit views. By repeatedly experiencing certain aspects of a field, one gradually becomes an expert in that field. Experts are usually able to recognize meaningful patterns faster than novices (Chi 2006; Dreyfus 2004); they intuitively identify what should be done and seem to not even think about it. They just do what normally works, and of course, it usually works (Dreyfus 2004). Nevertheless, experts are often unable to verbalize how they knew what to do (the 'know how', Bjorklund 2008), meaning that they know more than they can recount (Polanyi 1966). Experienced teachers hold implicit knowledge and views that usually enable them to function automatically (Stolpe and Bjorklund 2012; Ainley and Luntley 2006). Much of teachers' activities in the classroom are patterns of behavior that they can invoke and perform without any conscious effort. Experienced teachers seem to organize their views of students and classrooms in particularly effective patterns that can be retrieved unconsciously from their long-term memory via classroom cues (Johansson and Kroksmark 2004). These patterns are not stored as conscious propositional knowledge or views, because teachers need their 'working memories' for the classroom matters at hand. Consequently, tacit knowledge and views are used to store non urgent practical patterns, and teachers are usually unaware of most of the practical patterns they use for teaching (Dudley 2013).

The American psychologist George Kelly formulated a psychological theory which might explain the notion of tacit views as nonverbal, unconscious cognitive constructs that control experts' decisions and actions. Kelly (1955) argued that people have different views of events in the world. These views are organized uniquely within each person's cognitive structure. Kelly established the Personal Construct Psychology (PCP) theory which argues that each person makes use of personal unique views, or constructs, which help him or her give meaning to events. The PCP theory states that people's views of the objects and events with which they interact are made up of a collection of related similarity-difference dimensions, referred to as personal constructs (Kelly 1955, 1969). Kelly drew explicit parallels between the processes that guide scientific research and those involved in everyday activities (Duit and Glynn 1996). Like scientists, people tend to predict and control the course of events in their environment using their personal cognitive constructs (Kelly 1955; Jankowicz 2001).

Following the consolidation of the PCP theory, Kelly designed a method to elicit personal constructs, namely tacit views, which is known as the Repertory Grid Technique (RGT). The RGT has been used in clinical psychology for more than 50 years but has recently found new uses in a variety of research areas. Eliciting tacit knowledge and views in the area of science education has been previously used for probing students' system thinking skills (Ben-Zvi Assaraf and Orion 2005; Keynan et al. 2014), exploring the perceptions held by a university geology instructor and his students (Bezzi 1999), exploring possible relationships between teachers' conceptions about science and the types of inquiry activities in which they engage students (Bencze et al. 2006), and investigating the change in teachers' reflections on the nature of science while teaching a new syllabus (Henze et al. 2007). The methodology and use of the RGT has been described in detail ((Rozenszajn and Yarden Teachers' views about the knowledge required for teaching and their tacit views about the relationships between CK and PCK, submitted)) and is briefly described in the 'Methods' section.

In this study, we focused on the following research questions: 1 . What are the participating mathematics teachers' views about the knowledge that is required for teaching? 2. What are the participating mathematics teachers' tacit views about the relationships between CK and PCK? 3. What are the differences between the participating biology and mathematics teachers' views of the 
knowledge required for teaching and on the relationships between CK and PCK? To examine this research question, we used the RGT, which has been previously used to elicit biology teachers' tacit views (Rozenszajn and Yarden 2014a) as well as other experts' tacit personal constructs (e.g., Jankowicz 2001; Fransella et al. 2004).

\section{Methods}

\section{Research context}

The context of this study is a unique professional development program for outstanding high-school science and mathematics teachers entitled 'The Rothschild-Weizmann Program for Excellence in Science Education', given at the Weizmann Institute of Science. The aim of this program is to provide a learning environment that will enrich the participating teachers' knowledge in both contemporary topics in science or mathematics education theories. Supplying a theoretical and practical foundation that seems compatible with teachers' experiences may provide an accessible way of making teachers aware of their teaching and learning procedures (Von Glasersfeld 1989; Even 2008), thereby leading to professional development (Eylon and Bagno 2006; Tytler et al. 2011; Rozenszajn and Yarden 2014b).

The Rothschild-Weizmann program which served as the context for this research is especially designed for high-school science (physics, chemistry, biology) and mathematics teachers who hold a Bachelor of Science (BSc) degree in science or mathematics and are studying toward a Master of Science (MSc) degree in science education (without thesis) in the course of the program. The program's curriculum runs for $8 \mathrm{~h}$ twice a week for four semesters (two academic years). Each semester, the teachers participate in different courses in science or mathematics and in science or mathematics education courses, according to their professional discipline. In this study, we focused only on the mathematics and biology teachers who participated in this program during 2009 to 2011.

Five science and mathematics education courses (two academic points each) are offered to the students from both disciplines. The courses are: i) Introduction to Science (or Mathematics) Education; ii) Cognition Learning and Instruction; iii) Assessment Methods in Science and Mathematics Education; iv) Integration of Learning Technologies, and v) History and Philosophy of Science. In addition, courses in the teachers' respective disciplines are given to develop their CK. The courses, which include contemporary topics in science or mathematics, are taught by leading scientists from the Weizmann Institute of Science. In addition, the participating teachers take two to five courses that focus on field-related education issues which are aimed at enriching the teachers' knowledge in science or mathematics education in their related disciplines. The aim of these courses is to enrich teachers' professional knowledge in their discipline, and they are taught by leading science education researchers from the Weizmann Institute of Science.

\section{Research population}

The population of this study consisted of a total of 13 in-service high-school mathematics teachers and 16 highschool biology teachers who participated in the RothschildWeizmann program described above. The biology teachers were part of a larger population that participated in our previous study aimed at revealing biology teachers' tacit views of the knowledge required for teaching biology (Rozenszajn and Yarden 2014a). The 16 biology teachers who took part in the current study included only teachers who studied during the academic years 2009 to 2011, similar to the participating mathematics teachers. Thus, all of the teachers studied the five science and mathematics education courses given during the course of the program together. At the beginning of the program, the teachers held a BSc degree in mathematics or biology and had between 4 and 22 years of teaching experience. The teachers taught in a variety of high schools - national, religion-oriented, and boarding schools.

All of the mathematics and biology teachers participated in courses that were aimed at bridging the gap between their practice and newly acquired knowledge. The mathematics teachers studied one course that was aimed at bridging the gap between studies that explore the teaching of geometry and the teaching practice. Another course was aimed at bridging the gap between studies that explore the teaching of algebra and teaching practice. The biology teachers participated in a long-term workshop aimed at designing new teaching and learning materials based on their knowledge, needs, and knowledge newly acquired in the program (Rozenszajn and Yarden 2014b). This study's population and context are very specific; therefore, the results and the conclusions of this study will refer only to this study's population and context.

\section{The repertory grid technique}

The RGT draws out the interviewees' tacit views on a given topic and encourages them to confront their intuitions - to make the tacit explicit (Jankowicz 2001). Researchers who choose to use this elicitation technique argue that it is free from external influences (Bezzi 1999; Fransella et al. 2004; Henze et al. 2007; Jankowicz 2004; Ben-Zvi Assaraf and Damri 2009). Every grid consists of four components: topic, elements, constructs, and ratings. These components are usually elicited in a four-step procedure between an interviewer and an interviewee. Elicitation of elements (alternative events, states, or entities) and constructs (dimensions of similarity and difference 
between elements) is central to the tacit views' representation in repertory grids (Bradshaw et al. 1993).

We followed the four steps of the full RGT, with each group of teachers separately, during the second semester of the first or second year of the Rothschild-Weizmann program. The four steps were: (i) introducing the topic: we explained to the mathematics or biology teachers that we were interested in their views on the knowledge that is required for teaching mathematics or biology, respectively; (ii) eliciting the elements: each teacher was asked to write down 12 elements that represent the knowledge that is required for teaching their discipline on 12 separate cards; (iii) eliciting personal constructs: each teacher was asked to randomly pick three cards and write down the listed elements in a table, each element in a separate column. Then, he or she was asked to choose the exceptional element of the three, circle it, and write down in a fourth column the reason that two of the elements were similar and the third one exceptional. The teachers were asked to repeat this action ten times. Repeated explanations for choosing the exceptional elements were subsequently defined as constructs; (iv) rating the connection between the elements and constructs: each teacher was then asked to write down the opposite of a given construct, meaning that he or she had to define the construct poles. Then the teacher was given an empty table and asked to write the poles of each construct at opposite ends of each row. Next, he or she was asked to write each element at the top of each column in the upper row and rate the correlation between each element and each construct on a five-point scale in which ' 1 ' means 'totally agree with the left pole of the construct' and ' 5 ' means 'totally agree with the right pole of the construct' (Rozenszajn and Yarden 2014a).

After collecting the data, content and cluster analyses were performed (Jankowicz 2004; Rozenszajn and Yarden, 2014a). For the content analysis, the repertory grid elements of each teacher's group were pooled and categorized according to the meanings they expressed. The categories were derived bottom-up from the elements themselves, by identifying the various themes they expressed (Rozenszajn and Yarden 2014a; Rozenszajn and Yarden 2014b). The content analysis enabled us to compare the biology and mathematics teachers' elements for an initial characterization of the teachers' views on the elements of knowledge required for teaching their disciplines (for the definitions of each category see the 'Results' section).

Then, a cluster analysis of the elements and a cluster analysis of the constructs were performed independently. Over $80 \%$ similarity between elements or between constructs is considered high coherence between the repertory grid's elements or constructs (Kelly 1969). The distance between elements or between constructs is considered a 'safe' measure for examining the association among elements or constructs (Fransella et al. 2004). The meaning of the high coherence between elements or constructs allowed us to identify the relationships between elements or constructs, thus presenting an image of each teacher's personal view - 'a precise statement of the way in which the interviewee thinks of or gives meaning to the topic in question' (Jankowicz 2004). We then searched for more than $80 \%$ coherence between CK elements and other elements' categories and more than $80 \%$ coherence between the CK constructs and other constructs' categories, thus enabling identification of the teachers' tacit views of the relationships between their CK and PCK.

\section{Validation of the RGT}

According to Kelly (1969), validity of the RGT is equated with its usefulness. Thus, many studies are performed using the PCP theory and the RGT as a way of determining whether the grids are of value for them. Fransella et al. (2004) presented a massive assortment of studies performed since 1977 which found the RGT to be useful in clinical settings, education, language acquisition, forensic work, market research, politics, and organization and business applications.

We performed semi-structured interviews for further interpretive validation with four of the mathematics teachers and five of the biology teachers. During the interviews, each teacher was presented with their grid map and our interpretations of it, and they were asked to express their views on the accuracy of the results.

During the interviews, the teachers were also asked the following questions: (a) Do you see any relationships between the subject matter courses studied in the program and your practice in class? (b) If 'yes', in what way are they related? The interviews were transcribed and qualitatively analyzed. That is, we searched for explanations that referred to possible relationships between teachers' CK and PCK.

In addition, we ran a focus group with six mathematics education researchers and two biology education researchers (the two authors). The results of the current study were presented and the researchers were asked: (a) Can you explain the relationships between CK and PCK among the mathematics teachers' results? (b) How can the differences between the mathematics and biology teachers' results be explained? The discussion in the focus group was recorded and qualitatively analyzed according to Shkedi (2003). We looked carefully for explanations that strengthened the teachers' answers in the interviews (according to Shkedi 2003).

\section{Data sources}

The data sources of this study were as follows: (i) all repertory grid elements and constructs were collected; (ii) all repertory grid rating tables were collected and 
the data were uploaded to REPGRID version 5 software (www.repgrid.com) for clustering analysis and for creating the repertory grid diagram (for an example see Figure 1); (iii) interviews with four mathematics teachers and five biology teachers were recorded, transcribed, and analyzed; (iv) a focus group discussion of the six mathematics and two biology education researchers was recorded, transcribed, and analyzed.

\section{Results}

Mathematics teachers' views about the knowledge that is required for teaching

To create repertory grid diagrams, each mathematics teacher who participated in this study was asked to write down 12 elements that represent the knowledge that is required to teach his or her discipline. Each teacher $(n=13)$ managed to elicit between 9 and 12 elements. The mathematics teachers elicited a total of 151 elements, which were classified according to their content into eight different categories (following, Rozenszain and Yarden 2014a; Rozenszajn and Yarden 2014b): (i) teaching strategies, the ways a teacher should teach, such as 'clear explanations', 'the ability to simplify complex processes', and 'the ability to exemplify'; (ii) meaningful learning, the factors that influence meaningful learning, such as 'students' misconceptions' and 'difficulties in comprehending a specific idea', (iii) relevance, the connection between contents taught in class and students' everyday world, such as 'updated in the students' world and respecting it, and 'uses concepts of the student's everyday life'; (iv) curriculum, the general learning goals of the curriculum as well as the activities and materials to be used in meeting those goals, such as 'being familiar with the syllabus' and 'knowledge of the curriculum'; (v) subject matter $C K$, the biology teachers mentioned various elements of science contents, such as 'biological knowledge,' the human body,' 'ecology', and 'deep knowledge in science'. The mathematics teachers mentioned only 'knowledge in mathematics' without referring to any specific mathematical topic; (vi) general pedagogy, pedagogy and education in general, such as 'pedagogical knowledge' and 'knowledge in education'; (vii) teacher's personality, personal characteristics of the teacher that may influence teaching, such as 'creative,' 'moral personality', and 'likes mathematics'; and (viii) learner's personality, students' personal characteristics that may influence learning, such as 'understands students' personality'.

The first four categories (i to iv) can be aligned with PCK categories suggested in the literature (Rozenszajn and Yarden 2014b). Thus, in this study, we referred to these four elements' categories as PCK elements. The fifth category, namely CK, was a category of elements which have been previously reported as distinct from PCK (Shulman 1986; Magnusson et al. 1999; Grossman 1990; Rozenszajn and Yarden 2014a). The last three categories (vi to viii) were not aligned with previously suggested PCK or CK categories.

A close examination of the elements elicited by the teachers revealed that each teacher possesses a different repertoire of mathematics elements that he or she views as elements that are required for teaching. The diversity of the elements elicited by the mathematics teachers revealed that most were from five categories (Table 1): teaching strategies, meaningful learning, teacher's personality, CK, and general pedagogy. The other categories included elements that were mentioned at less than $10 \%$ of the total number of elements elicited in each discipline. It is worth noting that elements from the CK category

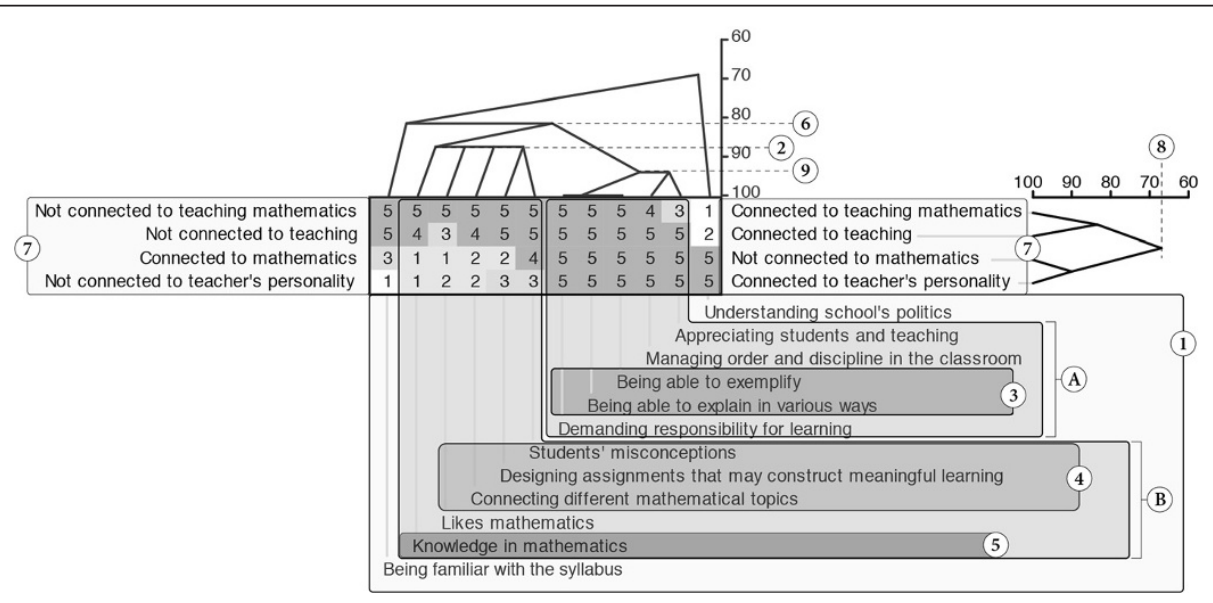

Figure 1 Analysis of a mathematics teacher's data (Teacher M11) using a repertory grid tree diagram. (1) Elements: (A) a group of elements with high coherence; (B) another group of elements with high coherence; (2) Coherence rate between the elements in group B; (3) and (4) Groups of PCK elements; (5) CK element; (6) Coherence rate between the elements in groups A and B; (7) Constructs; (8) Coherence rate between the constructs: 'Connected to teaching mathematics' and 'Not connected to mathematics'; (9) Coherence rate between the elements in group A. 
Table 1 The percentage of elements in each category that were mentioned by the mathematics and biology teachers

\begin{tabular}{lllllllll}
\hline & $\begin{array}{l}\text { Teaching } \\
\text { strategies }\end{array}$ & $\begin{array}{l}\text { Meaningful } \\
\text { learning }\end{array}$ & Relevance & Curriculum & CK & $\begin{array}{l}\text { General } \\
\text { pedagogy }\end{array}$ & $\begin{array}{l}\text { Teacher's } \\
\text { personality }\end{array}$ & $\begin{array}{l}\text { Learner's } \\
\text { personality }\end{array}$ \\
\hline Mathematics teachers & 25 & 13 & 2 & 3 & 20 & 11 & 25 & 1 \\
Biology teachers & 23 & 12 & 3 & 0 & 35 & 0 & 24 & 3 \\
\hline
\end{tabular}

were mentioned by all of the teachers, whereas elements from the other categories were mentioned only by several teachers. Namely, all 13 mathematics teachers participating in this study mentioned CK elements as required for teaching mathematics (not shown).

\section{Mathematics teachers' tacit views on the relations between CK and PCK}

We subsequently focused on analyzing the coherence rate between the CK and PCK elements. For the RGT, each teacher was asked to fill in a table in which each element was rated relative to each construct. The computed outcome of the ratings given by each teacher formed a twodimensional tree diagram, a cluster, which represented similarities between rating patterns of the elements and similarities between rating patterns of the constructs.

One of the mathematics teachers' clusters, Teacher M11, is shown here as a case study (Figure 1). Teacher M11 elicited 12 elements that she viewed as important for mathematics teaching ( 1 in Figure 1 ). The rate of similarity (in percentages) between the different elements appears at the top of the diagram, in the coherence-rate scale (left of 2, 6, and 9 in Figure 1). The graph to the left of the element coherence-rate scale shows the similarity rate between the elements that are attached to each line $(2,6$, and 9 , in Figure 1). In Teacher M11's cluster, there were two groups of elements that showed high coherence (more than 80\%) within the elements of each group. The first group (A in Figure 1), whose elements were $95 \%$ coherent (9 in Figure 1), included five elements as follows: appreciating students and teaching (Teacher's personality category); managing order and discipline in the classroom (General pedagogy category); being able to exemplify; being able to explain in various ways (PCK category), and demanding responsibility for learning (General pedagogy category). Since we were looking for connections between CK and PCK, it is important to note that the two PCK elements: 'being able to exemplify' and 'being able to explain in various ways' (3 in Figure 1) constituted a $100 \%$ coherence rate (in addition to the $100 \%$ coherence rate between those elements and the general pedagogy element: demanding responsibility for learning). The second group ( $\mathrm{B}$ in Figure 1), with an $88 \%$ coherence rate (2 in Figure 1), also included five elements as follows: 'students' misconceptions'; 'designing assignments that may construct meaningful learning', and 'connecting different mathematical topics' (PCK category, 4 in Figure 1); 'likes mathematics' (Teacher's personality category) and 'knowledge in mathematics' (CK category, 5 in Figure 1). Namely, the three PCK elements showed 88\% coherence with the CK element ( 2 in Figure 1). In addition, these three PCK elements were highly coherent with a teacher's personality element: 'likes mathematics'. Moreover, the two groups of elements (A and B) also showed high coherence between them (82\%, 6 in Figure 1). That is, PCK elements were highly coherent with the CK element.

The analysis of all of the participating mathematics teachers' clusters shows that all of their clusters (100\%) demonstrated high coherence (more than 80\%) between different CK elements and that $77 \%$ of the mathematics teachers' clusters demonstrated high coherence between CK elements and PCK elements. Each of these teachers' clusters independently demonstrated high coherence (more than 80\%) between CK elements and different PCK elements. Namely, most of the mathematics teachers' clusters showed high coherence between CK and some PCK elements, whereas low coherence was observed between other PCK elements and the same CK elements.

A similar analysis was performed for the mathematics teachers' constructs. For example, Teacher M11 elicited four constructs which included one PCK construct: 'connected to teaching mathematics' (Teaching strategies category), one CK construct: 'connected to mathematics', one general pedagogy construct: 'connected to teaching', and one teacher's personality construct: 'connected to teacher's personality' (7 in Figure 1). During the interview, Teacher M11 explained that the construct 'connected to mathematics' refers to mathematical subject matter. Teacher M11's RGT cluster demonstrated high coherence (>80\%) between PCK ('connected to teaching mathematics') and general pedagogy and high coherence (>90\%) between CK ('connected to mathematics') and teacher's personality ('connected to teacher's personality'), but the coherence rate between the PCK and CK constructs was low (67\%, 8 in Figure 1).

Analyses of the constructs of each of the 13 mathematics teachers revealed that 12 of the teachers (92\%) elicited the CK construct during the RGT. Among the 12 clusters that mentioned CK, 8 showed a low coherence rate (less than $80 \%$ ) between CK and the other constructs. Three clusters showed high coherence between CK and teacher's personality, three clusters showed high coherence between CK and general pedagogy, and only one 
mathematics teacher's cluster showed high coherence between CK and PCK (not shown).

Taken together, most of the mathematics teachers' clusters showed a high coherence between CK and PCK elements, but a low coherence between CK and PCK constructs.

\section{Comparing the mathematics and biology teachers' tacit views of the knowledge required for teaching and of the relations between CK and PCK}

The biology teachers' tacit views of the knowledge required for teaching biology and of the possible relationships between their CK and PCK were previously examined using the RGT (Rozenszajn and Yarden 2014a). Here we referred to only part of the previous study's population, namely the biology teachers who studied in the same program during the same period as the mathematics teachers described above (the 2009 to 2011 academic years). Sixteen biology teachers who studied during those academic years elicited a total of 178 elements. Similar to the mathematics teachers, the biology teachers mentioned most often elements which can be classified into two PCK categories (teaching strategies and meaningful learning), elements that can be classified into the CK category, and elements that can be classified as teacher's personality elements. In addition, similar to the mathematics teachers' results, all 16 biology teachers mentioned CK elements as required for teaching biology, while the other elements were mentioned only by a few teachers (Table 2). The differences between the mathematics and biology teachers' elements were in their reference to the general pedagogy and curriculum elements. While some mathematics teachers mentioned these elements, none of the biology teachers did (Table 2).

To examine the relationships between CK elements and elements from other categories in the participating biology teachers' data, we looked at each of the 16 biology teachers' clusters and searched for high coherence (more than $80 \%$ ) between the CK elements and other elements mentioned by the teachers. This analysis showed more than $80 \%$ coherence between different CK elements within all biology teachers' clusters (100\%), but only $25 \%$ of the biology teachers' clusters showed high coherence between CK and PCK elements. That is, the CK elements were viewed as a separate and coherent group of elements by most of the biology teachers, similar to the results obtained from the bigger population that had participated in our previous study (Rozenszajn and Yarden 2014a). This result stands in contrast to the mathematics teachers' results, with only $25 \%$ of the biology teachers' clusters showing high coherence between PCK and CK elements vs. $77 \%$ of the mathematics teachers' clusters.

A similar analysis was performed for the constructs elicited by the biology teachers, which showed that 15 out of the 16 biology teachers (94\%) elicited CK constructs. Similar to the mathematics teachers' results, only one teacher's cluster showed high coherence between CK and PCK constructs (Rozenszajn and Yarden 2014a).

\section{Teachers' views on the relationships between CK and PCK} Mathematics teachers' views

Four mathematics teachers were interviewed for interpretative validation. Each teacher was presented with her or his cluster and our interpretations of it. The overall validation rate of the RGT clusters was $100 \%$, meaning that each of the four teachers that were interviewed explained the RGT results in their own words and these were fully aligned with our interpretation.

Data analysis of the mathematics teachers' interviews which served as a validation of the RGT results revealed that the mathematical courses that they studied during the program were very challenging for them. The courses' contents were not part of the themes that they teach in school. In addition, the mathematical courses required many complex exercises in mathematical problem-solving. However, while acquiring deep mathematical knowledge during the courses, the teachers learned different ways of solving various mathematical tasks. They believed that the mathematical courses enabled them to be more accurate in their teaching and to understand the variety of thinking paths taken by their students, namely that there might be more than one solution to each mathematical problem. For example, Teacher M11 whose cluster showed high coherence between the CK element: 'knowledge in mathematics' (5 in Figure 1) and the PCK elements: 'students' misconceptions'; 'designing assignments that may construct meaningful learning' (4 in Figure 1); ( $88 \%$ of coherence, Figure 1) said in her interview: 'the mathematical courses clarified to me that there is more than one way of solving a mathematical problem, that is important for teaching a diverse population of students. It also enabled me to build better assignments in order to clarify mathematical issues. I feel I understand my students' difficulties

Table 2 The percentage of mathematics and biology teachers that mentioned elements of each category

\begin{tabular}{lllllllll}
\hline & $\begin{array}{l}\text { Teaching } \\
\text { strategies }\end{array}$ & $\begin{array}{l}\text { Meaningful } \\
\text { learning }\end{array}$ & Relevance & Curriculum & CK & $\begin{array}{l}\text { General } \\
\text { pedagogy }\end{array}$ & $\begin{array}{l}\text { Teacher's } \\
\text { personality }\end{array}$ & $\begin{array}{l}\text { Learner's } \\
\text { personality }\end{array}$ \\
\hline Mathematics teachers & 92 & 77 & 15 & 31 & 100 & 69 & 85 & 15 \\
Biology teachers & 94 & 63 & 31 & 0 & 100 & 0 & 81 & 19 \\
\hline
\end{tabular}


better now.' That is, studying challenging mathematical issues together with other teachers and encountering diverse ways of thinking and problem-solving enabled her to better identify her students' difficulties. Moreover, it enabled her to deal with her students' learning difficulties more effectively.

Teacher M27, whose cluster also showed high coherence between CK and PCK elements (not shown), said: ' $I$ am a better teacher now. The courses were so challenging for us all but now I can understand the difficulties students have in learning mathematics. I try to understand their way of thinking and help them accordingly. Obviously, different students think differently, that does not mean they are always wrong.' That is, the advanced mathematics courses enabled teacher M27 to better understand her students' difficulties in learning mathematics and enabled her to be more sensitive to her students' different ways of thinking. Thus, their studies in the mathematical courses enabled the teachers to better understand the diversity of their students' cognitive procedures and apply different teaching strategies to meet the diversity of their students' learning paths. Therefore, it can be suggested that learning mathematical contents enriched most of the mathematics teachers' PCK.

To further validate the results on the mathematics teachers' tacit views of the knowledge required for teaching mathematics and the relationships between CK and PCK, a focus group was conducted. We introduced the RGT method and this study's results to a group of mathematics education researchers who were familiar with the Rothschild-Weizmann program. Data analysis of the focus group discussion strengthened the results obtained from the teachers' interviews. It was revealed that dealing with high-level mathematical problems in the course of the Rothschild-Weizmann program challenged the mathematics teachers. That challenge may have created a dramatic shift in these teachers' status: 'from being an experienced teacher to a student with difficulties understanding and solving new problems' (one of the mathematics education researchers). It was suggested that this shift in turn enabled the mathematics teachers to better understand their students' difficulties in solving new mathematical problems. It was further suggested that learning high-level mathematical contents enabled the teachers to understand mathematics at the conceptual level and therefore to reorganize their knowledge. This, in turn, caused the mathematics teachers to be more open to different solutions for mathematical problems and perhaps also to be more creative in their teaching using different teaching strategies so as to appeal to different learning styles.

\section{Biology teachers' views}

Analysis of the biology teachers' interviews revealed that, by and large, the biology teachers were expecting to learn new biological contents in the professional development program and their expectations were met. Acquiring new biological contents in the program helped the teachers answer questions raised by students in the classroom more accurately. For example, Teacher B11 whose cluster showed a low coherence rate between CK and PCK elements (less than 70\%, data not shown) said: 'Before studying here I could provide more general answers to questions related to biological knowledge. Now, after learning here, I answer more accurately. I know and understand more and I can provide more specific answers.' The other biology teachers declared during their interviews that they tend to insert more updated contents into their lessons. The opportunities to accurately answer their students' questions in class and to insert newly acquired contents into their teaching were connected with raising the teachers' confidence in class. In contrast, Teacher B9, who was one of the four teachers whose cluster showed high coherence between CK and PCK elements (more than $80 \%$, data not shown) said: 'I need content knowledge but it is not the most important thing in teaching biology. Teaching strategies is more important. To be able to explain abstract issues, to identify how much a certain student really understands. I get excited from teaching strategies, not content knowledge.' It should be noted that Teacher B9 was unique in her view toward PCK. Most of the biology teachers were more excited about studying updated biological CK during the professional program than studying pedagogical issues.

\section{Discussion}

It has been previously suggested that investigating the relationships between various professional knowledge components may shed light on the nature of PCK and on its role in teachers' practice (Friedrichsen et al. 2011; Abell 2008; Park et al. 2011). In this study, we investigated the participating mathematics teachers' views on the knowledge required for teaching, as well as their tacit views on the relationships between CK and PCK, and compared them to those of the participating biology teachers. The results of our study implied that the participating mathematics teachers tend to view CK as an important component of teaching knowledge. Moreover, the participating mathematics teachers tended to view CK and PCK as related entities. These results are reinforced by previous studies which reported that for mathematics teachers, the relationship between CK and PCK seems to be strong (Blömeke, 2011 in Juttner et al. 2013).

The comparison between the mathematics and biology teachers' clusters suggests that CK is a significant component of professional knowledge for both, because CK was the only category of elements that was elicited by all mathematics and all biology teachers in the course of the RGT. However, in contrast to the mathematics teachers, 
the participating biology teachers tended to view CK as separate from PCK. These results are reinforced by previous studies showing a statistically low but significant measured relationship between PCK and CK of biology teachers (Juttner et al. 2013; Rozenszajn and Yarden 2014a).

CK has a unique meaning for the participating mathematics teachers' practice, which was found to be different from its meaning for the participating biology teachers' practice. Mathematics teachers do not often need to update their mathematical knowledge for their practice, at least not at the same pace as biology teachers. In this study, we found that the challenge of learning high-level mathematical contents during professional development programs enabled the participating mathematics teachers to better understand their students' difficulties. This finding stands in line with a previous research that showed that advanced mathematics courses are viewed by the teachers as a resource for reminding teachers what learning mathematics feels like and that it improved their sensitivity to students' difficulties (Even 2011). Moreover, this study shows that the participating mathematics teachers believe that their understanding of the various ways their students think improved. Thus, enriching the participating teachers' CK enabled them to enrich their PCK. For most of the participating biology teachers, one can assume that new CK will be viewed as a challenge in their practice because the field of biological sciences is in rapid flux. Thus, biology teachers need to continuously update their CK throughout their teaching career. Accordingly, it is possible that biology teachers' CK is dynamically changing when they are exposed to contemporary biological topics. Biology teachers usually participate in professional development programs in which they are exposed to contemporary biological subject matter knowledge. In contrast, their PCK does not usually change at the same pace (Rozenszajn and Yarden 2014b). The fact that biology teachers need to stay updated with concurrent massive developments in biological knowledge may cause them to invest time and energy in this domain, thus neglecting the need to update their PCK. Therefore, it is possible that mathematics teachers can enrich their PCK while studying high-level mathematical contents, whereas the biology teachers view PCK and CK as separate entities and they form no connections between the two. Consequently, the discussion about relationships between teachers' CK and PCK should be carried out in the context of the relevant discipline. While CK may be considered an integral part of mathematics teachers' $\mathrm{PCK}$, as suggested by Ball et al. (2008), it may be considered separate from the PCK of biology teachers, as suggested by Shulman (1986).

The analysis of the teachers' CK constructs posed a dilemma. Most of the mathematics and biology teachers elicited CK constructs, meaning that they chose to sort the elements using CK constructs. The elicitation of CK constructs reinforced the idea that CK is an important factor in the teachers' views of the knowledge required by both disciplines' teachers for their practice. The low coherence obtained between CK constructs and the other constructs elicited by most of the biology teachers agrees with our conclusion that most of the biology teachers tend to distinguish their CK from PCK. But the low coherence between the CK and PCK constructs within most of the mathematics teachers' clusters contrasts with the high coherence that was identified between CK and PCK elements among the same mathematics teachers' clusters.

Constructs regarding teaching represent the ways in which teachers make sense of their practice. The constructs are bipolar in nature, i.e., they may be defined in terms of polar characteristics (Kelly 1955). Namely, by stating what ' $\mathrm{CK}$ ' is, one may also be stating what ' $\mathrm{CK}$ is not'. Therefore, constructs elicited during the RGT may provide a glimpse of how a person makes sense of his or her world (Jankowicz 2001). To explain the low coherence between CK and PCK constructs within most of the mathematics and biology teachers' clusters, it may be assumed that the teachers viewed the overall construct of CK as a separate entity of knowledge required for teaching. Furthermore, based on the fact that most of the mathematics teachers' clusters showed high coherence between CK and some PCK elements and while other PCK elements showed low coherence with the same CK elements, these teachers may be viewing only a part of their PCK as related to CK. Each teacher tended to view different elements of PCK as related to elements of $\mathrm{CK}$, but when it came to the overall construct of $\mathrm{CK}$, it might have been considered a unique construct by these teachers.

It is important in this study that we also examined the possibility that the teaching experience of the participating teachers might be correlated with their views about the relationships between CK and PCK, but we could not identify any correlation between the two. Namely, no differences were identified between the views of the more novice teachers, who graduated several years before studying in the program and probably posses a more updated CK, and the views of the more veteran teachers (data not shown).

Although the findings of this study are substantial, it is important to keep in mind that the findings are given in the context of a particular program and that the overall number of subjects who participated in the study is small. Therefore, we suggest continuing investigating the questions in the subject in other contexts and varied teachers' populations in order to enable to generalize the conclusions.

\section{Conclusions}

The main contribution of this study is in exposing that teachers from different disciplines may view differently 
the importance of high-level CK to their practice. Therefore, we suggest professional development programs designers to take these differences into account while designing these programs. In a transcript of an interview with Lee Shulman (Berry et al. 2008), he suggested 'bringing subject matter and teaching together'. This study clarifies some of the differences between the views of the participating high-school biology and mathematics in-service teachers with regard to the role of high-level CK to their practice and professional development.

The differences among the participating mathematics and biology teachers' tacit views of the relationships between CK and PCK may aid in the design of professional development programs for mathematics and biology teachers. We suggest investigating whether there is a need to promote the relationships between biology teachers' CK and PCK, because it cannot be assumed that increasing their CK will automatically improve their PCK (Gess-Newsome 1999; Rozenszajn and Yarden 2014b). Teachers' CK and related students' learning have been identified as one criterion of effective professional development. Therefore, the need to foster teachers' CK and PCK during the in-service phase may be a key component of an educational reform (Kleickmann et al. 2013). It is likely that even if teachers do relate CK to PCK to some extent in their practice, it is important to draw attention to their ability to recognize these relationships and articulate them during professional development programs. Making the tacit explicit may further promote teachers' professional development.

\section{Competing interests}

The authors declare that they have no competing interests.

\section{Authors' contributions}

RR conducted the study as part of her research towards a PhD degree in Science Teaching at the Feinberg Graduate School of the Weizmann Institute of Science. She designed the study, carried out the experiments that are described in this manuscript, and wrote up the text. AY contributed to the conception of the study and its design, as she was the PhD supervisor of the first author. She partially participated in the acquisition of the data and helped in interpreting the collected data and in writing the manuscript for publication. All authors read and approved the final manuscript.

\section{Acknowledgements}

We are thankful to the teachers who participated in this study, to the Rothschild-Weizmann Program for Excellence in Science Education, and to The Israel Science Foundation (grant No. 836/09) for funding.

Received: 11 June 2014 Accepted: 3 November 2014 Published online: 20 November 2014

\section{References}

Abell, SK. (2008). Twenty years later: does pedagogical content knowledge remain a useful idea? International Journal of Science Education, 30(10), 1405-1416.

Ainley, J, \& Luntley, M. (2006). Towards an articulation of expert classroom practice. Teaching and Teacher Education, 23(7), 1127-1138.

Ball, DL, Thames, MH, \& Phelps, G. (2008). Content knowledge for teaching what makes it special? Journal of Teacher Education, 59(5), 389-407.

Baumert, J, Kunter, M, Blum, W, Brunner, M, Voss, T, Jordan, A, Klusmann, U, Krauss, S, Neubrand, M, \& Tsai, YM. (2010). Teachers' mathematical knowledge, cognitive activation in the classroom, and student progress. American Educational Research Journal, 47(1), 133-180.

Ben-Zvi Assaraf, O, \& Damri, S. (2009). University science graduates environmental perceptions regarding industry. Journal of Science Education and Technology, 18(5), 367-381.

Ben-Zvi Assaraf, O, \& Orion, N. (2005). Development of system thinking skills in the context of earth system education. Journal of Research in Science Teaching, 42(5), 518-560

Bencze, JL, Bowen, GM, \& Alspo, S. (2006). Teachers' tendencies to promote student-led science projects: associations with their views about science. Science Education, 90(3), 400-419.

Berry, A, Loughran, J, \& van Driel, JH. (2008). Revisiting the roots of pedagogical content knowledge. International Journal of Science Education, 30(10), 1271-1279.

Bezzi, A. (1999). What is this thing called geoscience? Epistemological dimensions elicited with the repertory grid and their implications for scientific literacy. Science Education, 83(6), 675-700.

Bjorklund, L. (2008). The repertory grid technique: making tacit knowledge explicit: assessing creative work and problem solving skills. In H Middleton (Ed.), Researching technology education: methods and techniques. Netherlands: Sense.

Borko, H. (2004). Professional development and teacher learning: mapping the terrain. Educational Researcher, 33(8), 3-15.

Bradshaw, JM, Ford, KM, Adams-Webber, JR, \& Boose, JH. (1993). Beyond the repertory grid: new approaches to constructivist knowledge-acquisition tool development. In KM Ford \& JM Bradshaw (Eds.), Knowledge acquisition as modeling (pp. 287-333). New York: Wiley.

Chi, MTH. (2006). Two approaches to the study of experts' characteristics. In KA Ericsson (Ed.), The Cambridge handbook of expertise and expert performance (pp. 21-38). New York: Cambridge University Press.

Childs, A, \& McNicholl, J. (2007). Investigating the relationship between subject content knowledge and pedagogical practice through the analysis of classroom discourse. International Journal of Science Education, 29(13), 1629-1653.

De Jong, O, \& Van Der Valk, AE. (2007). Science teachers' PCK and teaching practice: learning to scaffold students' open-inquiry learning. In R Pinto \& D Couso (Eds.), Contributions from science education research (pp. 107-118). Dordrecht, The Netherlands: Springer.

Depaepe, F, Verschaffel, L, \& Kelchtermans, G. (2013). Pedagogical content knowledge: a systematic review of the way in which the concept has pervaded mathematics educational research. Teaching and Teacher Education, $34,12-25$.

Dreyfus, SE. (2004). The five-stage model of adult skill acquisition. Bulletin of Science, Technology \& Society, 24(3), 177-181.

Dudley, P. (2013). Teacher learning in lesson study: what interaction-level discourse analysis revealed about how teachers utilized imagination, tacit knowledge of teaching and fresh evidence of pupils learning, to develop practice knowledge and so enhance their pupils' learning. Teaching and Teacher Education, $34,107-121$.

Duit, R, \& Glynn, SM. (1996). Mental modeling (Research in Science Education in Europe; Current Issues and Themes). Routledge: Falmer Press.

Even, R. (2008). Facing the challenge of educating educators to work with practicing mathematics teachers. In B Jaworski \& T Wood (Eds.), International handbook of mathematics teacher education: The mathematics teacher educator as a developing professional. Rotterdam, The Netherlands: Sense.

Even, R. (2011). The relevance of advanced mathematics studies to expertise in secondary school mathematics teaching: practitioners' views. ZDM: The International Journal on Mathematics Education, 43(6-7), 941-950.

Eylon, B, \& Bagno, E. (2006). Research-design model for professional development of teachers: designing lessons with physics education research. Physics Education Research, 2(1), 1-14.

Fernandez-Balboa, J, \& Stiehl, J. (1995). The generic nature of pedagogical content knowledge among college professors. Teaching and Teacher Education, 11(3), 293-306.

Fransella, F, Bell, R, \& Bannister, D. (2004). A manual for repertory grid technique. Chichester, England: Wiley

Friedrichsen, PJ, Van Driel, JH, \& Abell, SK. (2011). Taking a closer look at science teaching orientations. Science Education, 95(2), 358-376.

Gess-Newsome, J. (1999). Pedagogical content knowledge: an introduction and orientation. In J Gess-Newsome \& NG Lederman (Eds.), Examining pedagogical content knowledge: PCK and science education (pp. 3-17). Dordrecht, The Netherlands: Kluwer

Grossman, PL. (1990). The making of a teacher: Teacher knowledge and teacher education. New-York: Teachers College Press. 
Henze, I, Van Driel, JH, \& Verloop, N. (2007). Science teachers' knowledge about teaching models and modeling in the context of a new syllabus on public understanding of science. Research in Science Education, 37(2), 99-122.

Hollon, R, Roth, K, \& Anderson, C. (1991). Science teachers' conceptions of teaching and learning. Advances in Research on Teaching, 2(2), 145-186.

Jankowicz, D. (2001). Why does subjectivity make us nervous? Making the tacit explicit. Journal of Intellectual Capital, 2(1), 61-73.

Jankowicz, D. (2004). The easy guide to repertory grids. Chichester: Wiley.

Johansson, T, \& Kroksmark, T. (2004). Teachers' intuition-in-action: how teachers experience action. Reflective Practice, 5(3), 357-381.

Juttner, M, Boone, W, Park, S, \& Neuhaus, BJ. (2013). Development and use of a test instrument to measure biology teachers' content knowledge (CK) and pedagogical content knowledge (PCK). Educational Assessment, Evaluation and Accountability, 25(1), 45-67.

Kelly, GA. (1955). The psychology of personal constructs (Vol. 1). New York: Norton and $\mathrm{CO}$.

Kelly, GA. (1969). Personal construct theory and the psychotherapeutic interview. In B Maher (Ed.), Clinical psychology and personality: the selected papers of George Kelly (pp. 224-232). New York: Wiley.

Keynan, A, Ben-Zvi Assaraf, O, \& Goldman, D. (2014). The repertory grid as a tool for evaluating the development of students' ecological system thinking abilities. Studies in Educational Evaluation, 41, 90-105.

Kleickmann, T, Richter, D, Kunter, M, Elsner, J, Besser, M, Krauss, S, \& Baumert, J. (2013). Teachers' content knowledge and pedagogical content knowledge: the role of structural differences in teacher education. Journal of Teacher Education, 64(1), 90-106.

Krauss, S, Brunner, M, Kunter, M, Baumert, J, Blum, W, Neubrand, M, \& Jordan, A. (2008). Pedagogical content knowledge and content knowledge of secondary mathematics teachers. Journal of Educational Psychology, 100(3), $716-725$.

Lederman, NG, \& Gess-Newsome, J. (1992). Do subject matter knowledge, pedagogical knowledge, and pedagogical content knowledge constitute the ideal gas law of science teaching? Journal of Teacher Education, 3(1), 16-20.

Lee, E, \& Luft, JA. (2008). Experienced secondary science teachers' representation of pedagogical content knowledge. International Journal of Science Education, 30(10), 1343-1363.

Loughran, J, Milroy, P, Berry, A, Gunstone, R, \& Mulhall, P. (2001). Documenting science teachers' pedagogical content knowledge through PaP-eRs. Research in Science Education, 31(2), 289-307.

Loughran, J, Mulhall, P, \& Berry, A. (2008). Exploring pedagogical content knowledge in science teacher education. International Journal of Science Education, 30(10), 1301-1320.

Magnusson, S, Krajcik, J, \& Borko, H. (1999). Nature, sources and development of pedagogical content knowledge for science teaching. In J Gess-Newsome \& NG Lederman (Eds.), Examining pedagogical content knowledge: PCK and science education (pp. 95-132). Dordrecht, The Netherlands: Kluwer academic publishers.

Marks, R. (1990). Pedagogical content knowledge: from a mathematical case to a modified conception. Journal of Teacher Education, 41(3), 3-11.

Park, S, Jang, J, Chen, Y, \& Jung, J. (2011). Is pedagogical content knowledge (PCK) necessary for reformed science teaching? Evidence from an empirical study. Research in Science Education, 41(2), 245-260.

Polanyi, M. (1966). The tacit dimension. Gloucester, MA: Doubleday and Co.

Rollnick, M, Bennett, J, Rhemtula, M, Dharsey, N, \& Ndlovu, T. (2008). The place of subject matter knowledge in pedagogical content knowledge: a case study of south African teachers teaching the amount of substance and chemical equilibrium. International Journal of Science Education, 30(10), 1365-1387.

Rozenszajn, R, \& Yarden, A. (2014a). Characterizing the tacit relationships between biology teachers' content knowledge (CK) and other professional knowledge components. In D. Krueger \& M. Ekborg (Eds.), A selection of papers presented at the 9th Conference of European Researchers in Didactics of Biology (ERIDOB) (pp. 73-85). Berlin, Germany. http://www.bcp.fuberlin.de/ biologie/arbeitsgruppen/didaktik/eridob_2012/eridob_proceeding/5-characterizing.pdf?1389177503

Rozenszajn, R, \& Yarden, A. (2014). Expansion of biology teachers' pedagogical content knowledge (PCK) during a long-term professional development program. Research in Science Education, 44(1), 189-213.

Schmelzing, S, Van Dreil, JH, Juttner, M, Brandenbusch, S, Sandmann, A, \& Neuhaus, BJ. (2013). Development, evaluation, and validation of a paper-and-pencil test for measuring two components of biology teachers' pedagogical content knowledge concerning the "cardiovascular system". International Journal of Science and Mathematics Education., 11(6), 1369-1390.

Shkedi, A. (2003). Words of meaning: qualitative research - theory and practice. Tel Aviv, Israel: Ramot (in Hebrew).

Shulman, LS. (1986). Those who understand: knowledge growth in teaching Educational Researcher, 15(2), 4-14.

Shulman, LS. (1987). Knowledge and teaching: foundation of the new reform. Harvard Educational Review, 57(1), 1-22.

Stolpe, K, \& Bjorklund, L. (2012). Seeing the wood for the trees: applying the dual-memory system model to investigate expert teachers' observational skills in natural ecological learning environments. International Journal of Science Education, 34(1), 101-125.

Tytler, R, Symington, D, \& Smith, C. (2011). A curriculum innovation framework for science, technology and mathematics education. Research in Science Education, 41(1), 19-38.

Van Driel, JH, \& Berry, A. (2012). Teacher professional development focusing on pedagogical content knowledge. Educational Researcher, 41(1), 26-28.

Von Glasersfeld, E. (1989). Cognition, construction of knowledge, and teaching. Synthesis, 80(1), 121-140.

Zeidler, DL. (2002). Dancing with maggots and saints: visions for subject matter knowledge, pedagogical knowledge and pedagogical content knowledge in science teacher education reform. Journal of Science Teacher Education, 13(1), 27-42

\section{doi:10.1186/s40594-014-0011-7}

Cite this article as: Rozenszajn and Yarden: Mathematics and biology teachers' tacit views of the knowledge required for teaching: varying relationships between CK and PCK. International Journal of STEM Education 2014 1:11.

\section{Submit your manuscript to a SpringerOpen ${ }^{\circ}$ journal and benefit from:}

- Convenient online submission

$\checkmark$ Rigorous peer review

- Immediate publication on acceptance

- Open access: articles freely available online

- High visibility within the field

- Retaining the copyright to your article

Submit your next manuscript at springeropen.com 